\title{
Prevalence of musculoskeletal pain in two primary care clinics in a mid-sized town's urban population in Malaysia
}

Esha Dasgupta, Jasmine Li Lin Yap, K. Kirosa Kunjunee, Xin Ying Choong, Wan Wen Soh, Meroshini Sundaran, Swan Sim Yeap, Keen Sang Tai

Dasgupta E, Yap JLL, Kunjunee KK, et al. Prevalence of Musculoskeletal Pain in Two Primary Care Clinics in a Mid-Sized Town's Urban Population in Malaysia. Malays Fam Physician. 2021;16(1);93-102. https://doi.org/10.51866/oa1102

\section{Keywords:}

Musculoskeletal pain,

Disability, Primary care clinic

\section{Authors:}

\section{Tai Keen Sang}

(Corresponding author)

MBBS, FRCP

Senior Lecturer, International

Medical University, Clinical Campus

Seremban, Negeri Sembilan

Malaysia

Email: keensangtai@imu.edu.my

\section{Esha Dasgupta}

MBBS, FRCP, FRCPI

Professor of Medicine, International Medical University, Clinical Campus Seremban, Negeri Sembilan Malaysia

\section{Jasmine Yap Li Lin}

Medical student, International Medical University, Clinical Campus Seremban, Negeri Sembilan Malaysia

\section{K. Kirosa Kunjunee Medical student, International Medical University, Clinical Campus Seremban, Negeri Sembilan Malaysia}

\section{Choong Xin Ying}

Medical student, International Medical University, Clinical Campus Seremban, Negeri Sembilan Malaysia

\section{Abstract}

Objective: This study assesses the prevalence of musculoskeletal (MSK) pain in patients attending primary care clinics in a medium-sized town in Malaysia and examines the interventions given for the symptoms and the level of the associated disabilities.

Method: This investigation comprises a cross-sectional descriptive study of all patients visiting two primary care clinics aged 18 years and above. Patients presenting with joint pain answered a questionnaire assessing demographic data, disabilities (measured by the Stanford HAQ-DI), and treatment options.

Results: Of 1,074 patients surveyed, 202 (18.8\%) had MSK complaints. The mean age of those with MSK pain was 56.1 years. Incidence increased with age, reaching $78.8 \%$ of those over 48 years of age. The knee was the most common site of MSK pain (52.2\%), with 20.3\% requiring referral for specialist assessment. The median HAQ score was 0.375 and $89.6 \%$ of those surveyed had mild disability.

Conclusion: MSK pain is a common problem among patients visiting primary care clinics. The most common site of MSK pain was the knee. On formal assessment, the majority of these patients exhibited mild disability. A significant proportion of patients still required specialist referral. This finding would suggest a need for further training on the management of MSK disease at the primary care level to avoid over-burdening the secondary care services.

\section{Introduction}

Rheumatic diseases contribute a significant burden to the population's health. In 2017, the Global Burden of Disease study found that musculoskeletal (MSK) disorders ranked fifth in terms of disability-adjusted life years (DALYs) per 100,000 population worldwide. $^{1}$ MSK disorders are the leading global contributor to disability, causing pain and limiting mobility and dexterity. ${ }^{2}$ Moreover, the prevalence of MSK disorders increases with age $^{2}$; thus, with an aging population worldwide ${ }^{3}$, the burden of MSK disorders can be expected to increase. In Malaysia, MSK disorders also ranked fifth in terms of DALYs per 100,000 population, similar to the global results. ${ }^{1}$ Like the rest of the world, Malaysia has an increasingly aged population, and the proportion of the population over the age of 65 is expected to rise from $10.5 \%$ in $2019^{4}$ to $14.5 \%$ in $2040 .^{5}$

In Malaysia, MSK pain was found to be the seventh most common complaint in a primary care setting, comprising $5.9 \%$ of the reasons for encounter (RFE), with back and knee pain representing the most commonly affected sites. ${ }^{6}$ In another study, $6.5 \%$ of visits to primary care clinics involved MSK pain, of which the back, knee, and shoulder were the most common complaints.?

In surveys carried out in Canada, the USA, and Western Europe, the prevalence of physical disabilities caused by a MSK disorder has been estimated at $4-5 \%$ of the adult population., The figures for functional disability are much higher. For example, in a study from Lebanon, the proportion of lifetime functional disability due to MSK problems was as high as onethird of the subjects. ${ }^{10}$ The prevalence is higher in women and increases with age. ${ }^{11}$ In a community-based study from Australia, 53.9\% of women and $37.6 \%$ of men aged between 65-74 experienced impairment of their activities of daily living (ADL) as measured by a Health Assessment Questionnaire score of $>0 .{ }^{12}$ In individuals over 85 years old, the proportion of those with impaired ADL rose to $89.6 \%$ in women and $73.2 \%$ in men. Accompanying the pain and disability was 


\author{
Soh Wan Wen \\ Medical student, International \\ Medical University, Clinical Campus \\ Seremban, Negeri Sembilan \\ Malaysia
}

\section{Meroshini Sundaran \\ Medical student, International \\ Medical University, Clinical Campus \\ Seremban, Negeri Sembilan \\ Malaysia}

\section{Yeap Swan Sim}

MB ChB, MD, FRCP

Consultant Rheumatologist, Subang Jaya Medical Centre, Subang Jaya Selangor, Malaysia also a reduction in the quality of life in people with MSK pain. In Malaysia, no previous surveys have evaluated the effect of MSK pain on the subjects' daily functioning/associated disabilities.

Therefore, this study was carried out in a medium-sized town in Malaysia to determine the prevalence and pattern of MSK pain in a primary care setting, the interventions given for the symptoms, and the level of associated disability in two primary care clinics.

\section{Materials and Methods}

\section{Population sampled}

A cross-sectional study was conducted in the public primary care clinics of Klinik Kesihatan Seremban (KKS) and Klinik Kesihatan Seremban 2 (KKS2) in Seremban, Malaysia, from June 2014 to January 2015. The inclusion criteria were all patients aged 18 and above presenting with a complaint of MSK pain on the day of the clinic visit. Of the approximately 32 patients per clinic, 1-2 patients decided not to participate. Thus, the refusal rate was around $6 \%(2 / 32)$.

\section{Study design}

The study staff went to the above clinics once a week, at which time all patients attending the clinic on those days were asked about their presenting complaint for that visit. Patients with MSK pain were asked whether they would like to participate in the study by completing the questionnaire while waiting to see the doctor. If they agreed, formal consent was made before the patients received the forms for self-completion. All the forms returned were fully completed.

The patients were asked to complete the survey instrument, which was a two-part questionnaire (see Appendix One). The first part was further divided into three sections: section A-questions about the respondent's general characteristics and personal details, section B-data on the MSK pain for that particular clinic visit, and section C-the interventions performed for the MSK pain, by both the patient and the attending doctor. A body chart indicating the names of body parts was used to assess the site of the MSK pain, and participants were asked to make tick marks against all the body parts that were painful. The second part of the questionnaire was the validated Stanford HAQ 20-Item Disability Scale (HAQ-DI) to assess a patient's level of functional ability. ${ }^{13}$ The HAQ-DI, which comprises 20 items in eight categories (dressing, arising, eating, walking, hygiene, reaching, gripping, and outside activity), is measured on a four-point ordinal scale from 0 to 3: 0 without any difficulty, 1 with some difficulty, 2 with much difficulty, and 3 unable to do. The highest score in each category is averaged into a disability index on a scale from 0 (no disability) to 3 (complete disability). The score is the average of the eight category scores, with a range of 0 to 3. From the original studies, scores of 0 to 1 are generally considered to represent mild to moderate difficulty; 1 to 2 , moderate to severe disability; and 2 to 3 , severe to very severe disability. ${ }^{13}$ For the purposes of our analysis, we classified those with scores of 1 and below $(\leq 1)$ to have mild disability, those with scores above 1 and up to 2 as having moderate disability, and those with scores above $2(>2)$ to have severe disability. The questionnaire was available in English and Malay. The scale has a Malay translation ${ }^{14}$ and has been found to be a sensitive, reliable, and valid instrument for the measurement of functional status in rheumatoid arthritis patients in Malaysia. ${ }^{15}$

The following information was obtained from the study population: the patients' sociodemographic data; the presence of MSK pain; the sites of MSK pain and the number of such sites; the interventions tried by the patients, including self-administered analgesia, massage, physiotherapy and/or complementary medicine (acupuncture and traditional herbal medicine); the number that required specialist referral; and an assessment of the degree of disability as measured by the Stanford HAQ 20-Item Disability Scale.

\section{Data analysis}

Data were analyzed using the Statistical Package for Social Sciences (SPSS) version 19 (IBM Corp., Armonk, NY, USA). The Shapiro-Wilk test for normality was used to check that the data were normally distributed. The mean and standard deviations were calculated for the numerical data, and categorical comparisons were analyzed using a chi-square test. A p-value of $<0.05$ was taken to be statistically significant. 


\section{Consent and Ethical Approval}

All subjects provided signed informed consent prior to inclusion in the study. This study was approved by the Joint Committee of the Research and Ethics Committee of the International Medical University [ID No. CScl Sem6(16)2014] and conducted in accordance with the ethical standards laid down in the 2013 Declaration of Helsinki.

\section{Results}

In all, 1,074 patients were approached in the KKS and KKS2 clinics. A total of 202 complained of symptoms of MSK pain and went on to complete the study questionnaires. Therefore, from this study, 202/1,074 (18.8\%) patients presented with a complaint of MSK pain to the primary health clinics.
Table 1 shows the patients' sociodemographic characteristics. Most of the respondents presenting with a complaint of musculoskeletal pain were female $(\mathrm{n}=114 ; 56.4 \%)$. The female-to-male ratio was found to be $1.3: 1$, with a mean age of $56.1 \pm 15.7$ (one standard deviation [SD]) years. Within the different ethnic groups, Indian patients had the highest proportion of MSK pain complaints (39.1\%), followed by Malays (31.7\%), Chinese (27.2\%), and others (2.0\%). Approximately $50 \%$ of patients with MSK pain were employed, while $47.5 \%$ stated that they had "no income." Patients with "no income" were further questioned to ensure that they had no regular income from any employment, including self-employment. Of those who had income, all earned less than RM4000 per month (approximately USD900). The prevalence of MSK pain complaints increased with age, as shown in Figure 1, reaching $78.8 \%$ in those over 48 years of age.

Table 1: Sociodemographic characteristics of patients studied.

\begin{tabular}{|c|c|}
\hline & Number of patients, $\mathrm{N}=202(\%)$ \\
\hline Age (years) $($ mean $\pm S D)$ & $56.1 \pm 15.7$ \\
\hline $\begin{array}{l}\text { Gender } \\
\text { Male } \\
\text { Female }\end{array}$ & $\begin{array}{c}88(43.6) \\
114(56.4)\end{array}$ \\
\hline $\begin{array}{l}\text { Ethnicity } \\
\text { Malay } \\
\text { Chinese } \\
\text { Indian } \\
\text { Others }\end{array}$ & $\begin{array}{c}64(31.7) \\
55(27.2) \\
79(39.1) \\
4(2.0)\end{array}$ \\
\hline $\begin{array}{l}\text { Marital Status } \\
\text { Single } \\
\text { Married } \\
\text { Divorced } \\
\text { Widowed }\end{array}$ & $\begin{array}{c}37(18.3) \\
158(78.2) \\
2(1.0) \\
5(2.5)\end{array}$ \\
\hline $\begin{array}{l}\text { Occupation } \\
\text { Employed/Self-employed } \\
\text { Unemployed/Retired } \\
\text { Housewife } \\
\text { Student }\end{array}$ & $\begin{array}{c}102(50.5) \\
57(28.2) \\
36(17.8) \\
7(3.5)\end{array}$ \\
\hline $\begin{array}{l}\text { Monthly Income } \\
\text { No income } \\
\text { Less than RM1000 } \\
\text { RM1001-4000 } \\
\text { RM4001-8000 }\end{array}$ & $\begin{array}{c}96(47.5) \\
30(14.9) \\
69(34.2) \\
7(3.5)\end{array}$ \\
\hline
\end{tabular}




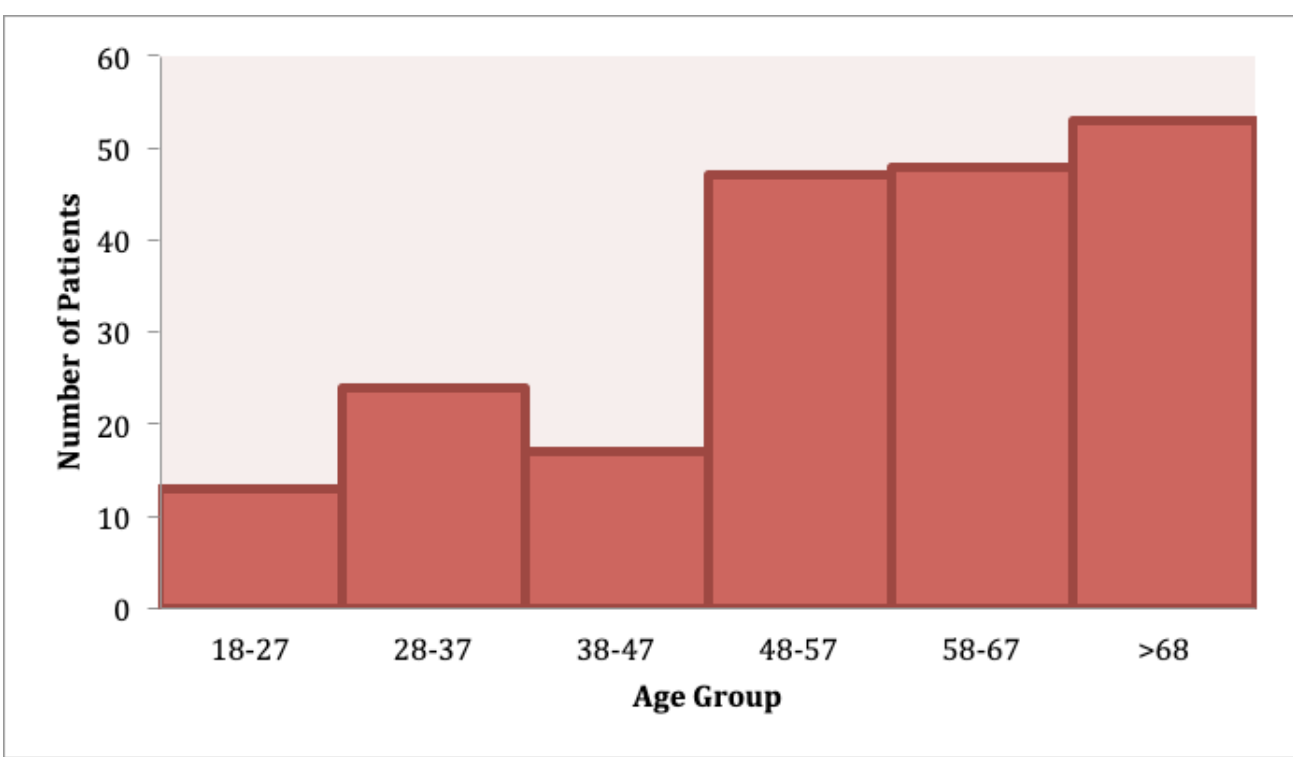

Figure 1: Number of patients with MSK pain in different age groups

The average number of painful sites per patient was $1.58 \pm 0.87$, with the majority $(59.9 \%)$ of the patients reporting MSK pain at only one site, followed by those with pain at two and three different sites $(28.7 \%$ and $5.9 \%$, respectively). Patients with MSK pain at four or more sites were found to be fewer in number, comprising only $5.5 \%$. The knee was found to be the most common site of MSK pain, accounting for $52.5 \%$ of the presenting complaints. The other sites of MSK pain complaints, in decreasing order of frequency, were the shoulder (17.3\%), ankle (17.3\%), back $(16.8 \%)$, hand $(15.8 \%)$, foot $(10.9 \%)$, wrist $(8.9 \%)$, elbow $(7.5 \%)$, neck $(5.9 \%)$, and hip (5.0\%).
Table 2 lists the interventions tried by patients prior to visiting the clinic, broken down by ethnicity. Most of the patients $(77.7 \%)$ had tried self-treatment before seeking medical help. Self-medication by oral analgesics was the most popular self-intervention tried by patients $(\mathrm{n}=91)$, followed by massage $(\mathrm{n}=76)$, while a smaller number used complementary medicine $(\mathrm{n}=29)$. No statistically significant association was noted between particular ethnicities and massage or oral analgesic use. However, for complementary medicine, we found that those of Chinese ethnicity appeared to have used this modality more commonly than Malays or Indians $(\mathrm{p}<0.05)$. Overall, 26.8\% (42/157) of the patients used more than one modality of self-intervention.

Table 2: Self-care practice by respondents in managing MSK pain by ethnicity.

\begin{tabular}{|l|c|c|c|c|}
\hline & Malay & Chinese & Indian & \multicolumn{1}{c|}{ Statistics } \\
\hline Massage & $28(36.8 \%)$ & $22(28.9 \%)$ & $26(34.2 \%)$ & $\chi^{2}=1.84, \mathrm{df}=2, \mathrm{p}=0.40$ \\
\hline Oral analgesics & $28(30.8 \%)$ & $27(29.7 \%)$ & $36(39.6 \%)$ & $\chi^{2}=0.35, \mathrm{df}=2, \mathrm{p}=0.84$ \\
\hline Complementary medicine & $7(24.1 \%)$ & $14(48.3 \%)$ & $8(27.6 \%)$ & $\chi^{2}=7.13, \mathrm{df}=2, \mathrm{p}=0.03$ \\
\hline
\end{tabular}

Following their visits to the clinic, $20.3 \%$ of patients were referred for a specialist opinion, and $12.4 \%$ were referred for physiotherapy.

The burden of disease disability was calculated using the Stanford-HAQ-DI. The median HAQ-DI score was 0.375 , with a mode of zero. Of the total, $89.6 \%$ of the patients presented with mild disability, 9.4\% exhibited moderate disability, and only $1 \%$ reported severe disability.

\section{Discussion}

Seremban is the state capital of Negeri Sembilan, one of the smaller states in Malaysia. The town covers an area of 948 $\mathrm{km}^{2}$, with a population of 555,935 in 2010. ${ }^{16}$ Seremban has four public primary care clinics. This study was done in two of the bigger clinics, which would be representative of the patients seen in public clinics in Seremban. However, the ethnic mix in the clinics showed an over-representation of Indians, 
who comprised $39.1 \%$ of the study sample, and an under-representation of Malays, who represented $31.7 \%$ of the patients. The general Malaysian population in 2010 was composed of $50.1 \%$ Malays, $22.6 \%$ Chinese, $11.8 \%$ indigenous, and $6.7 \%$ Indians, with "other" races numbering $8.9 \% .{ }^{17}$ The ethnic breakdown of Seremban in 2010 is similar to the general population-Bumiputera (Malay $\&$ indigenous) $56.3 \%$, Chinese $26.2 \%$, and Indians $17.0 \% .{ }^{16}$ Nevertheless, we feel that this ethnic breakdown is likely to be representative of the patients attending public (non-fee paying) clinics in Malaysia, as other studies have shown a higher proportion of Indian patients attending public clinics. ${ }^{18}$

The overall prevalence of MSK pain in our study was $18.8 \%(202 / 1074)$ in patients attending public clinics in Seremban. This finding is a marked increase compared to two previous studies of MSK pain presenting to primary care clinics in Malaysia, where only $5.9 \%$ and $6.5 \%$ had MSK pain, ${ }^{6,7}$ respectively. This difference might be a consequence of an aging population. In a previous populationbased Malaysian study from a semi-rural area, the prevalence of MSK pain was $21.1 \%{ }^{19}$ in the community, a finding very similar to this study. Thus, another hypothesis could be that people are more ready to seek medical assessment for their MSK pain nowadays that in the earlier studies. Compared to neighboring countries in the region, the prevalence of MSK pain was $23.6 \%$ in rural Indonesia and $31.3 \%$ in urban Indonesia, $17.6 \%$ in rural Thailand, and $28.4 \%$ and $16.2 \%$, respectively, in rural and urban areas in the Philippines. ${ }^{20-23}$ In Australia, musculoskeletal complaints accounted for $14.1 \%$ of patients' reasons for encounter (RFE) in general practice. ${ }^{24}$

This study recorded a slight preponderance of females $(56.4 \%)$ with MSK pain, which would be in keeping with previous studies showing that more females suffer from MSK pain. 919 Within the various ethnic groups, Indian females had the highest levels of MSK pain, which is in keeping with the previous study from Malaysia. ${ }^{7}$ In a laboratory model of pain, Malaysian females were found to have lower pain thresholds compared to males, but there was no difference between ethnic Malays, Chinese, or Indians. ${ }^{25}$ The most common site of MSK pain was the knee, in $52.5 \%$ of patients. This finding contrasts with the other studies in Malaysia that indicated back pain as the most common site of MSK pain. ${ }^{6,719}$ The majority of the respondents, $77.7 \%$, reported having tried to relieve their musculoskeletal pain on their own before seeing a doctor. Some of the modalities used included massaging the affected area, over-the-counter pain medication, acupuncture, and usage of complementary medicine. The Malaysian Community Oriented Programme for Control of Rheumatic Diseases (COPCORD) survey found that $58.8 \%$ of those with MSK pain self-medicated, with $17.7 \%$ using complementary medicine. ${ }^{19}$ That survey's results showing $17.7 \%$ using complementary medicine in the community is very similar to our study's finding of $14.5 \%$ (29/202) patients. However, there is a difference between the COPCORD study and our study in the usage of complementary medicine by different ethnic groups. In the COPCORD study, $21.8 \%$ of the Malays had tried complementary medicine compared to only $10.0 \%$ of the Chinese. ${ }^{19}$ In contrast, our study showed that the Chinese were more likely to use complementary medicine, with $48.3 \%$ utilizing it compared to only $24.1 \%$ of the Malays. One possible reason for the difference may be that the COPCORD study had more young subjects (only 12.6\% of the study population was over age 55), whereas our study's subjects had an average age of 56.1 years. One study demonstrated that Chinese who were older were more likely to have health beliefs suggesting that traditional Chinese medicine has fewer side effects and may possibly cure the underlying problem, compared to taking "Western" medicine. ${ }^{26}$ In a survey of the Malaysian Chinese public, $94 \%$ had sought traditional Chinese medicine, and $90 \%$ believed that it is acceptable to combine traditional Chinese medicine and modern medicine. ${ }^{27} \mathrm{~A}$ general survey of the Malaysian population found that the lifetime use of complementary medicine was $69.4 \%$, $88.9 \%$ of which were biological-based (herbs, vitamins, and supplements) therapies. ${ }^{28}$ This study of 6,947 respondents noted no difference in complementary medicine use when comparing educational level or working status. Thus, it may be that our results would be applicable to the wider population.

In this study, $20.3 \%$ of respondents from primary care were referred to Hospital Tuanku Jaafar, the main public hospital in Seremban, for further management. This outcome is similar to the Australian general practice data showing a referral for specialist care in 16.1 per 100 patient encounters. ${ }^{24}$ 
The Stanford 20-item HAQ has two core measurement scales: the disability index (HAQ-DI) and the pain scale, as well as its assessment of global health status. ${ }^{13}$ This 2-page HAQ is one of the most frequently used instruments for evaluating functional status and has established itself as a valuable, effective, and sensitive tool for the measurement of health status. ${ }^{29}$ Although initially developed for patients with arthritis, this instrument has also been used in normal aging populations, making it relevant for use in our study population, as not all those with MSK pain have been diagnosed with arthritis. ${ }^{29}$ With a median score of 0.375 , our patients would be considered to have mild disability, comparable with average scores that have been reported in a population-based study of $0.49 .{ }^{29}$

This study has several limitations that may reduce its widespread applicability. First, although the overall number of patients approached in the clinic was reasonable, we only obtained a sample size of 202 . However, we feel that it is an adequate number to determine the prevalence of patients with MSK pain attending the clinic. The higher proportion of Indians and those with low income reflects the population attending non-fee paying clinics. These limitations should be addressed in future studies having a larger sample encompassing patients across socioeconomic groups and including both rural and urban populations. In addition, for further studies, questionnaires in Tamil may be required to ensure that the data is accurately captured for the Indian population. However, some of our results, such as more MSK pain in females and those of Indian ethnicity, have agreed with other studies in Malaysia, which would suggest that this study has some external validity in terms of MSK pain prevalence.

\section{Conclusion}

This study assessed the prevalence of MSK pain among patients visiting two primary care clinics in an urban setting located in Seremban, Malaysia. MSK pain was a common complaint in those attending these clinics. Among patients with MSK pain, the majority exhibited mild disability, as measured by the Stanford HAQ 20Item Disability Scale. A significant proportion of these patients still required specialist referral, which suggests a need for further training on the management of MSK disease at the primary care level to avoid over-burdening the secondary care services.

\section{Competing interests and funding}

We do not have any competing interests for this study. This study was funded by the International Medical University, Malaysia.

\section{Acknowledgments}

We would like to thank the clinic directors for their permission to conduct research at their Centres and the International Medical University, Malaysia, for its support. We would also like to acknowledge the invaluable advice and assistance of Professor CL Teng, Department of Primary Care Medicine, International Medical University, Seremban, Negeri Sembilan, Malaysia, in the planning, development, and conducting of this study.

\section{Ethics Approval}

This study was approved by the Joint Committee of the Research and Ethics Committee of the International Medical University [IDNo.CSc/ Sem6(16)2014].

\section{References}

1. Institute for Health Metrics and Evaluation/ Global Health Data Exchange/Viz Hub. Available from: https://vizhub.healthdata.org/ gbd-compare/

2. World Health Organization/Home/ Newsroom/Fact sheets/Detail/Musculoskeletal conditions, dated 29 November 2019. Available from: https://www.who.int/newsroom/fact-sheets/detail/musculoskeletalconditions
3. United Nations DoEaSA: World Population Ageing 2009. 2010, New York.

4. Department of Statistics Malaysia/ Current Population Estimates, Malaysia 2018-2019. Available from: https://www. dosm.gov.my/v1/index.php? r=column/ cthemeByCat\&cat=155\&bul_id=aWJZRkJ4 UEdKcUZpT2tVT090Snpydz09\&menu_id =L0pheU43NWJwRWVSZklWdzQ4TlhUU T09\#: :text=The $\% 20$ composition $\% 20$ of $\% 20$ the $\% 20$ population, $70.0 \% 20$ per $\% 20$ cent $\% 20$ in $\% 202019$
5. Department of Statistics Malaysia/Population Projected (Revised) 2010-2040, dated 4 November 2016. Available from: https://www. dosm.gov.my/v1/index.php?r=column/pdfPrev \&id=Y3kwU2tSNVFDOWp1YmtZYnhUeV BEdz09

6. Mimi O, Tong SF, Nordin S, et al. A comparison of morbidity patterns in public and private primary care clinics in Malaysia. Malaysian Family Physician 2011;6(1):19-25. 
7. Zailinawati AH, Teng CL, Kamil MA, et al. Pain morbidity in primary care-preliminary observations from two different primary care settings. Med J Malaysia 2006;61(2):162-7.

8. Reynolds DL, Chambers LW, Badley EM, et al. Physical disability among Canadians reporting musculoskeletal diseases. J

Rheumatol 1992;19:1020-30

9. Woolf AD, Pfleger B. Burden of major musculoskeletal conditions. Bull World Health Organ 2003;81(9):646-56.

10. Slim ZN, Dowli A, Chaaya M, et al. Coping and disability: evidence from a developing country. Int J Rheum Dis 2011;14(1):61-67.

11. Fejer R, Ruhe A. What is the prevalence of musculoskeletal problems in the elderly population in developed countries? A systematic critical literature review. Chiropr Man Therap 2012;20: 31

12. March LM, Brnabic AJ, Skinner JC, et al. Musculoskeletal disability among elderly people in the community. Med J Aust. 1998;168(9):439-442.

13. Bruce B, Fries JF. The Stanford Health Assessment Questionnaire (HAQ): a review of its history, issues, progress, and documentation. J Rheumatol 2003;30:167-8.

14. ePROVIDE. Available from: https://eprovide. mapi-trust.org/instruments/health-assessmentquestionnaire

15. Hussein H, Mustafa R, Quek KF, et al. Cross-cultural adaptation and validation of the Malay health assessment questionnaire for use in rheumatoid arthritis. Int J Rheum Dis 2008;11:237-240.
16. Citypopulation.de. Available from: https:// www.citypopulation.de/en/malaysia/admin/ negeri_sembilan/0505_seremban/

17. The World Factbook, Malaysia. Available from: https://www.cia.gov/library/ publications/the-world-factbook/geos/my.html

18. Shahrir M, Shahdan M, Shahid M, et al. Multicentre survey of rheumatoid arthritis patients from Ministry of Health Rheumatology Centres in Malaysia. Int J Rheum Dis 2008;11:287-92.

19. Veerapen K, Wigley RD, Valkenburg $\mathrm{H}$. Musculoskeletal pain in Malaysia: a COPCORD Survey. J Rheumatol 2007;34:207-13

20. Darmawan J, Valkenburg HA, Muirden KD, et al. Epidemiology of rheumatic diseases in rural and urban populations in Indonesia: a World Health Organization-International League Against Rheumatism COPCORD Study, Stage I, Phase 2. Ann Rheum Dis 1992;51:525-8.

21. Chaiamnuay P, Darmawan J, Muirden KD, et al. Epidemiology of rheumatic disease in rural Thailand: a WHO-ILAR COPCORD study. J Rheumatol 1998;25:1382-7.

22. Manahan L, Caragay R, Muirden KD, et al. Rheumatic pain in a Philippine village-a WHO-ILAR COPCORD study. Rheumatol Int 1985;5:149-53.

23. Dans LF, Tankeh Torres S, Amante CM, et al. The prevalence of rheumatic diseases in a Filipino urban population: a WHOILAR COPCORD study. J Rheumatol 1997;24:1814-9.
24. Britt H, Miller GC, Henderson J, et al. General practice activity in Australia 2015-16. General practice series no. 40. Sydney: Sydney University Press, 2016. Available from: <purl. library.usyd.edu.au/sup/9781743325131>

25. Gupta E, Zailinawati AH, Lim AW, et al. Are Indians and females less tolerant to pain? An observational study using a laboratory pain model. Med J Malaysia 2009;64(2):111-3.

26. Lai DW, Surood S. Chinese health beliefs of older Chinese in Canada. J Aging Health 2009; 21(1):38-62.

27. Chew KS, Tan TW, Ooi YT. Influence of Chinese cultural health beliefs among Malaysian Chinese in a suburban population: a survey. Singapore Med J 2011;52(4):252-6.

28. Siti ZM, Tahir A, Farah AI, et al. Use of traditional and complementary medicine in Malaysia: a baseline study. Complement Ther Med 2009;17(5-6):292-299.

29. B, Fries JF. The Stanford Health Assessment Questionnaire: dimensions and practical applications. Health Qual Life Outcomes 2003;1:20. 


\section{Appendix One: Questionnaires Used}

\section{Questionnaire for Prevalence of Musculoskeletal Pain}

All questions contained in this questionnaire are strictly confidential.

\begin{tabular}{|l|l|l|l|}
\hline Part A & Socio-Demography \\
\hline Name(Last, First, M.I.): & Gender: $\square \mathrm{M} \square \mathrm{F}$ & Age: \\
\hline Marital status: & $\square$ Single $\square$ Married $\square$ Divorced $\square$ Widowed \\
\hline Ethnicity: & $\square$ Malay $\square$ Chinese $\square$ Indian $\square$ Others \\
\hline Occupation: & $\begin{array}{l}\square \text { Pensioner } \square \text { Professional } \square \text { Self-employed } \square \text { Skilled manual/ } \\
\text { Clerical } \square \text { Unskilled manual } \square \text { Housewife } \square \text { Unemployed } \quad \square \\
\text { Student }\end{array}$ \\
\hline
\end{tabular}

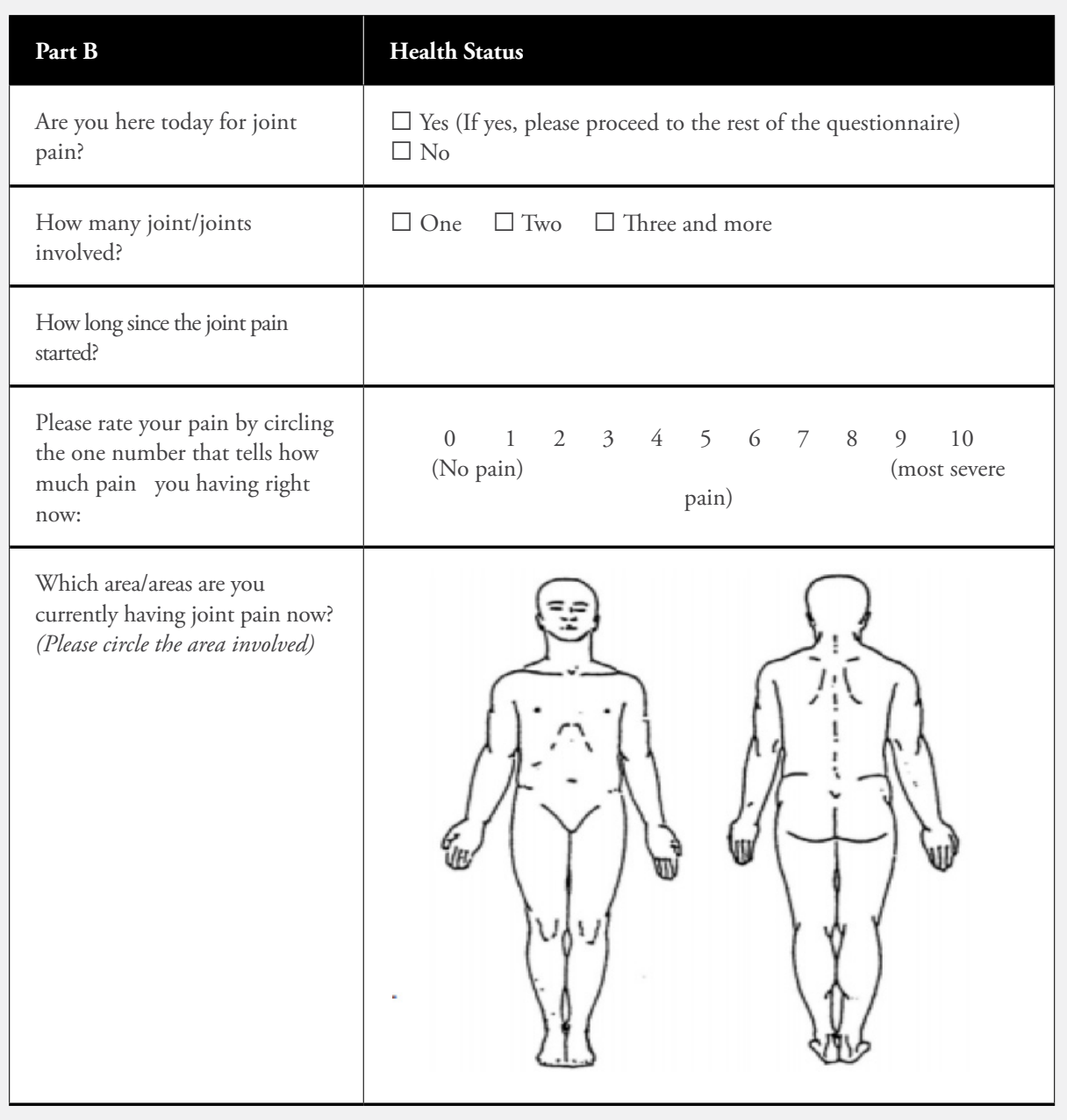

\begin{tabular}{|l|l|} 
Part C & Intervention for joint pain \\
\hline $\begin{array}{l}\text { How do you manage the joint } \\
\text { pain? }\end{array}$ & $\begin{array}{l}\square \text { Massage } \square \text { Analgesic tablet } \square \text { Acupuncture } \\
\square \text { Traditional Herbal } \square \text { Physiotherapy } \\
\square \text { Others: }\end{array}$ \\
\hline
\end{tabular}




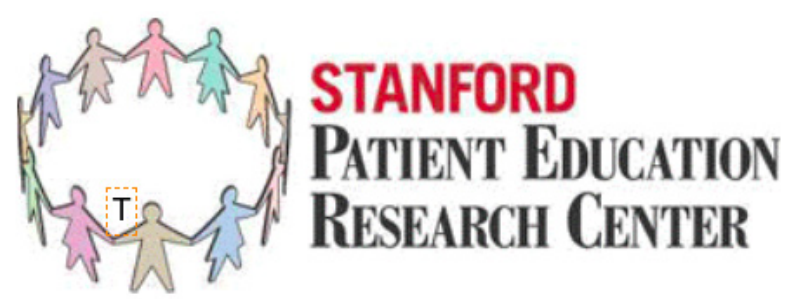

\section{Stanford HAQ 20-Item Disability Scale}

Please check $(\checkmark)$ the one best answer for your abilities over the past week

\begin{tabular}{|c|c|c|c|c|}
\hline At this moment, are you able to & $\begin{array}{l}\text { Without } \\
\text { ANY } \\
\text { difficulty }\end{array}$ & $\begin{array}{l}\text { Without } \\
\text { SOME } \\
\text { difficulty }\end{array}$ & $\begin{array}{l}\text { Without } \\
\text { MUCH } \\
\text { difficulty }\end{array}$ & $\begin{array}{c}\text { UNABLE } \\
\text { to do }\end{array}$ \\
\hline
\end{tabular}

\section{DRESSING \& GROOMING}

1. Dress yourself, including shoelaces and buttons?

2. Shampoo your hair?

$\begin{array}{llll}\square & \square & \square & \square \\ \square & \square & \square & \square\end{array}$

\section{ARISING}

3. Stand up from an armless straight chair?

4. Get in and out of?

$\square \quad \square$

$\square \quad \square \quad \square$

EATING

5. Cut your meat?

6. Lift a full cup or glass to your mouth?

7. Open a new milk carton?

$\begin{array}{llll}\square & \square & \square & \square \\ \square & \square & \square & \square \\ \square & \square & \square & \square\end{array}$

\section{WALKING}

8. Walk outdoors on flat ground?

9. Climb up five steps?

$\square$ $\square$

$\square$ $\square \quad \square$

$\square$

Please check any AIDS OR DEVICES that you usually use for any of the above activities:

$\square$ Devices used for dressing $\quad \square$ Built up or special utensils $\square$ Crutches

(button hook, zipper pull, etc) $\square$ Cane $\square$ Wheelchair

$\square$ Special or built up chair

$\square$ Walker

Please check any categories for which you usually need HELP FROM ANOTHER PERSON

$\square$ Dressing and grooming $\quad \square$ Arising $\quad \square$ Eating

$\square$ Walking

\section{HYGIENE}

10. Wash and dry your body?

11. Take a tub bath

12. Get on and off the toilet?

$\begin{array}{lll}\square & \square & \square \\ \square & \square & \square \\ \square & \square & \square\end{array}$


Please check $(\checkmark)$ the one best answer for your abilities over the past week

At this moment, are you able to

$\begin{array}{cccc}\text { Without } & \text { Without } & \text { Without } & \\ \text { ANY } & \text { SOME } & \text { MUCH } & \text { UNABLE } \\ \text { difficulty } & \text { difficulty } & \text { difficulty } & \text { to do }\end{array}$

\section{REACH}

13. Reach and get down a 5-pound object (such as a bag of sugar) from just above your head?

14. Bend down to pick up clothing from the floor

\section{GRIP}

15. Open car doors?
16. Open previously opened jars?
17. Turn faucets on and off?

$\begin{array}{llll}\square & \square & \square & \square \\ \square & \square & \square & \square \\ \square & \square & \square & \square\end{array}$

\section{ACTIVITIES}

18. Run errands and shop?

19. Get in and out of a car?

20. Do chores such as vacuuming or yard work?

$\square$

$\square$

$\square$

$\square$

$\square$

Please check any AIDS OR DEVICES that you usually use for any of the above activities:

$\square$ Raised toilet seat $\quad \square$ Bathtub bar $\quad \square$ Long-handled appliances for reach

$\square$ Bathtub seat $\quad \square$ Long-handed appliances in the bathroom

$\square$ Jar opener (for jars previously opened)

Please check any categories for which you usually need HELP FROM ANOTHER PERSON
$\square$ Hygiene
$\square$ Gripping and opening things
$\square$ Reach
$\square$ Errands and chores 